\title{
Immunohistochemical study of collagen types in human foetal lung and fibrotic lung disease
}

\author{
ED BATEMAN, M TURNER-WARWICK, BC ADELMANN-GRILL
}

From the Department of Medicine, Cardiothoracic Institute, Brompton Hospital, London and Max-Planck-Institut für Biochemie, München, Germany

ABSTRACT Highly purified type-specific anti-collagen antibodies (prepared in animals to types I, II, III, and IV bovine collagen) were used in an indirect immunofluorescence method for the study of human lung collagen. The tissue localisation of each collagen type, and the apparent type I:III collagen ratio was assessed in normal foetal and adult lung and in fibrotic lung lesions. In the latter, the relationship of the findings to the natural history of the lesion was considered. This method was compared with routine connective tissue stains. The following observations were made. (1) Foetal lung in the canalicular phase of development proved a useful substrate for validating and standardising the procedure. (2) Collagen fluorescence was more sensitive than connective tissue stains in detecting collagen in foetal tissues and sites of early fibrosis. (3) On the basis of collagentype fluorescence, two distinctive patterns of fibrosis were recognised. Areas of mature collagen surrounding vessels and bronchi and in established scar tissue, for example in asbestotic pleural plaques, were virtually exclusively type I collagen. By contrast, areas of early active fibrosis like sarcoid nodules and organising pneumonia, which usually contained variable numbers of fibroblasts and chronic inflammatory cells, were characterised by an increased proportion of type III collagen and a greater intensity of both types I and III collagen fluorescence. The possible significance of this change in type III: I collagen ratio is discussed. Determination of the stage of fibrotic lesions by this method might have applications in the prediction of disease progression, and influence management of some conditions.

Human tissues have been found to contain at least five idiotypes of the collagen molecule, all of which have also been isolated from the lung. ${ }^{1-5}$ Type I collagen, as in other organs, is the most plentiful, the majority being associated with the bronchial tree and blood vessels. A small amount is found in lung interstitium. ${ }^{1}$ Type I fibrils are packed tightly and form fibres of great tensile strength. ${ }^{6}$ Type III collagen constitutes a larger proportion of foetal than of adult tissues ${ }^{7}$ and usually exists in fibrils of smaller diameter than type.$^{8}$ The presence of type III collagen is thought to permit multidirectional flexibility, an important property in a compliant structure like the lung. Type II collagen has been found only in cartilaginous tissue and in the vitreous body of the eye. ${ }^{9}$ In the lung it is confined to tracheal and bronchial cartilage. ${ }^{2}$ The collagens type IV and $\mathrm{V}$ are present in basement membranes, and therefore lie adjacent to the endothelial, epithelial,

Address for reprint requests: Dr ED Bateman, Department of Medicine, UCT Medical School, Observatory 7925, South Africa. and smooth muscle cells from which they are produced. ${ }^{3} 810$ They may provide support for these cells and also contribute to the filtering function of the basement membranes. ${ }^{8}$

Biochemical analysis is the principal method of determining the proportions of these various molecules from tissue samples. Quantitation of the collagen types is difficult, however, since total extraction is seldom achieved and their solubility depends on several properties including the degree of cross-linking between collagen molecules. 711 Furthermore, in most tissues anatomical localisation of collagen types is not possible even when careful dissection techniques are coupled with the extraction procedure. On the other hand, the isolation, purification, and immunochemical characterisation of collagen types has resulted in the development of well-defined antibodies to each collagen type, which can be used both for quantitation of extracted collagens and for identification of these types by immunohistological techniques. The latter methods permit precise anatomical localisation of collagen 
types in tissue sections. The antibodies employed are raised in animals, and isolated from antisera by immunoadsorption on immobilised antigens. ${ }^{12} 13$ Their specificity and potency are characterised by radioimmunoassay. Although, for technical reasons these antibodies are usually raised to bovine collagens, there is a substantial cross-reactivity of bovine and human collagens and these antibodies have been used successfully in the study of human tissues. ${ }^{12} 13$

In the present report we describe the use of typespecific antibodies in the immunofluorescence study of collagen in several forms of pulmonary fibrosis and demonstrate their value for determining the relative amounts and distribution of collagen types in lung tissue at various stages of the fibrotic process.

\section{Methods}

\section{TISSUE SPECIMENS}

Human foetal lung of 20 weeks gestational age from a therapeutic abortion and samples of normal adult human skin and kidney from surgical specimens were obtained. Samples of normal and diseased adult lung and pleura were obtained from diagnostic open lung biopsy, lobectomy, or pneumonectomy specimens. All tissues were snap frozen fresh on carbon dioxide ice, and stored at $-70^{\circ} \mathrm{C}$ before sectioning. Four micron serial sections were cut from each on a Bright's cryostat, air dried, and stained by immunofluorescence techniques or fixed in formaldehyde for histochemical staining.

\section{COLLAGEN ANTIBODIES}

Antibodies to native (triple-helical) bovine collagen, types I, II, and III were raised in guinea pigs and isolated by immunoadsorption on Sepharose-linked collagen of the corresponding type. ${ }^{14}$ Their specificity was verified by radioimmunoassay. ${ }^{15}$ A preparation of purified antibodies to bovine type IV collagen raised in rabbits was a generous gift from Professor AJ Bailey (Agricultural Research Council, Langford, Bristol).

\section{TISSUE IMMUNOFLUORESCENCE}

The type-specific collagen antibodies were used as the first reactant in an indirect immunofluorescence technique. The second reactant was fluorescein isothiocyanate-conjugated (FITC) immunoglobulin to guinea-pig or rabbit IgG (gamma-chain specific) prepared in rabbits or goats respectively (Miles-Yeda Ltd, Rehovat, Israel). The former was used for types I, II, and III collagen fluorescence, and the latter for type IV. The optimal dilutions of first and second reactants were determined in a chess-board titration on human adult kidney and skin, and foetal lung, and used on all subsequent tissue specimens.

Serial sections of equal thickness from each tissue were stained with one of four collagen antibodies. Comparisons were made on corresponding structures and sites in consecutive sections. The semiquantitative assessment of the ratio of type I and type III collagen was based on combined evaluation of intensity of fluorescence and profusion of fluorescent fibres in each location, and scored on a four point scale (absent or equivocal,,$+ 2+$ or $3+$ ). On control sections of each tissue anti-collagen antibodies were omitted, or substituted with normal guinea-pig serum (complement-preserved, Wellcome Reagents Ltd, Beckenham, England) or rabbit serum. Microscopy was performed by one observer, and a single preparation of first and second layer reactants were used. Minimal interbatch variation and repeatability with this standardised technique was confirmed by examination of sections from a single sample of foetal lung in each batch, and by the study of some pathological specimens on two or more occasions.

The sections were examined on a Reichert "Zetopan" research microscope with ultraviolet light source for transmitted light, widefield immersion darkfield condenser, and a camera attachment for photography. Filters included a heat stopping filter (Schott and Genossen KG2/2 mm), a primary exciter filter (Schott and Genossen UG/1.5 mm) and secondary protective filters (Wratten $2 B / 3 \mathrm{~mm}$ and Schott GG $13 / 3 \mathrm{~mm}$ and $1 \mathrm{~mm})$. This combination permitted better histological orientation and contrast between specific apple-green fluorescence and non-specific autofluorescence than that obtained with incident light systems, because tissues not stained by FITCconjugate appeared as various shades of blue (depending on their refractile properties), instead of black or dull yellow-green as occurred with incident light. Orientation and adequate contrast between true and false fluorescence was found to be important in the study of tissues like diseased lung because confusing distortion of architecture is common.

\section{HISTOCHEMICAL STAINS}

Serial sections of each tissue were also stained with each of the following: haematoxylin and eosin, modified Glees' "reticulin" silver impregnation, ${ }^{16}$ Miller's elastin van Giesen and Masson's trichrome $\stackrel{\mathcal{O}}{+}$ stains ${ }^{17}$ and examined on a Nikon Apophot (Nippon 0 Kogaku KK) light microscope with AFM photomicrographic attachment.

The clinical history and course of each patient was only revealed when the tissue assessment had been completed. 

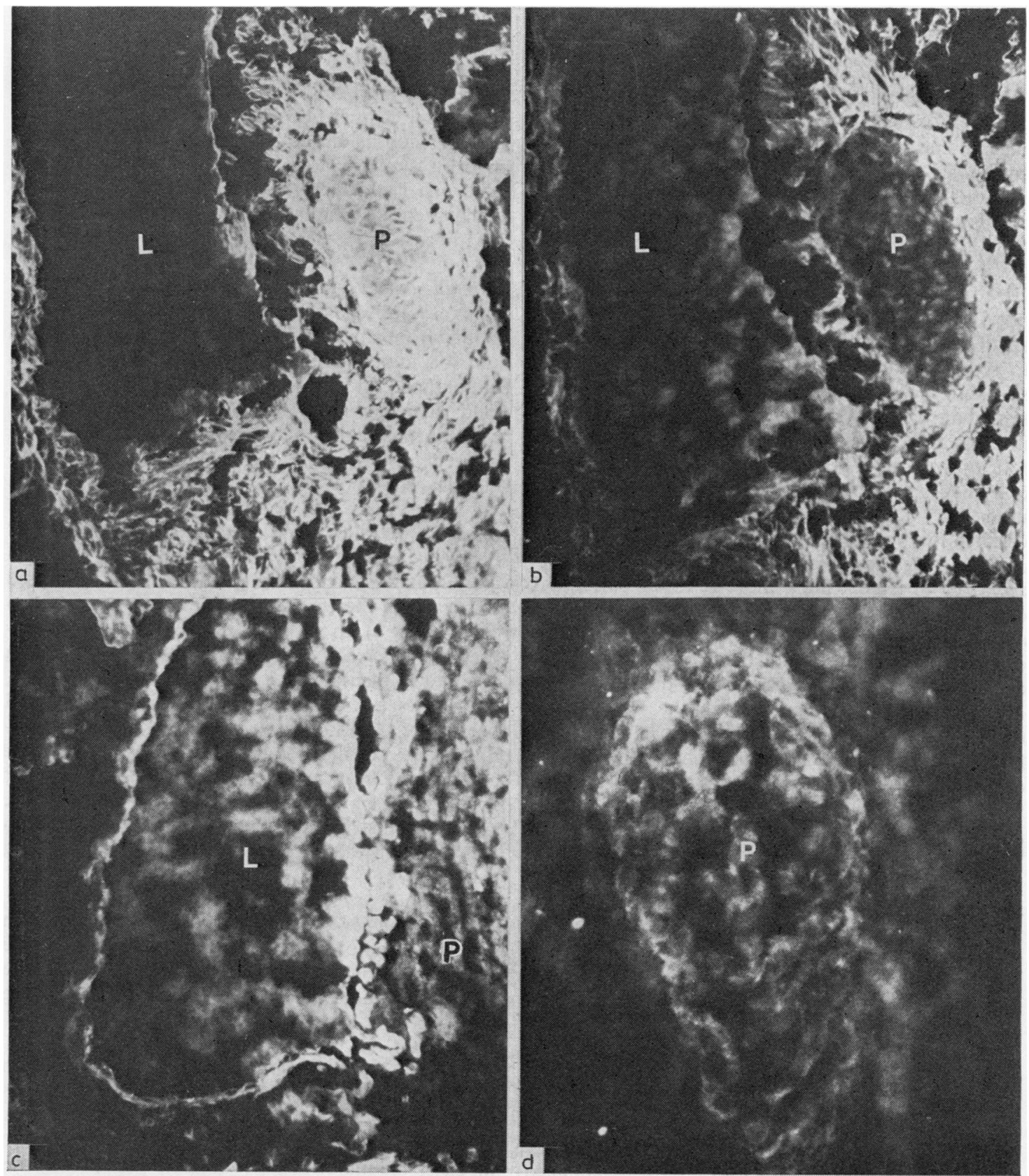

Fig 1 Photomicrographs of type-specific collagen fluorescence in oblique serial sections of human foetal bronchus (20 weeks gestation), obtained with an indirect immunofluorescence technique. In original preparations, transmitted ultraviolet light gave complete colour contrast between apple-green specific collagen fuorescence and blue autofluorescence of unstained tissues (seen here as ill-defined "fluffy" white areas). (a) Type I collagen fuorescence in bronchial wall and entire developing cartilage plate $(P)$. Bronchial lumen marked $L$. (b) Type III collagen fluorescence in bronchial wall but not in cartilage plate. The chondrocytes shown appeared blue. (c) Type IV collagen fuorescence delineating folds in bronchial mucosal basement membrane. No fluorescence in cartilage (a, $b, c$ original magnification $\times 400)$. (d) Type II collagen fluorescence confined to cartilage plate (original magnification
$\times 800)$ 
Results

FOETAL LUNG

This tissue at the canalicular phase of development (sixteenth to twenty-fourth week) served as a reference tissue for evaluation of the anti-collagen antibodies. The bronchial walls contain cartilaginous plates which stained for type I and type II collagen (fig 1). Whereas type II was confined to this site, type $I$. was plentiful in all other layers of the developing bronchus, except the mucosa. Type III collagen was not found in cartilage but in all other sites it occurred in association with type $I$, in smaller quantities. The apparent ratio of type III to type I collagen in foetal lung was similar in all sites and higher than in adult lung. The fluorescent semiquantitation for both types I and III collagen in the walls of different structures decreased in the following order: arteries, bronchi, pleura, veins, and budding alveolar sacs. Although the microscopy used did not provide sufficient resolution for detailed study of differences in fibrillar forms of these collagen types, in alveolar walls the type III collagen appeared to have a finer, more reticular pattern. A distinctive linear fluorescent appearance lining alveoli, bronchi, blood vessels, and pleura was obtained with type IV collagen antibodies (figs 1 and 2). In bronchi, the characteristic convolution of the mucosal basement membrane was evident (fig 1). Outlining basement membrane in this way helped orientation of tissue sections and definition of anatomical structures in foetal lung.

\section{ADULT LUNG}

The relative amounts of type I and type III collagen in different sites in normal and diseased lungs are shown in the table. Normal alveolar walls contained minimal amounts of type I collagen and barely detectable amounts of type III collagen. Pleural, peribronchial, and perivascular fibrous tissue contained only small amounts of type III collagen, and even type I collagen fluorescence was weaker than in the same sites in foetal lung. An exception to this ratio of type I to III fluorescence was found in bronchial submucosa and subintima of vessels, where similar amounts of type I and III collagen fluorescence were observed.

As demonstrated in foetal lung, type II collagen was confined to bronchial cartilage in both normal and diseased tissues studied. Type IV collagen formed a continuous lining in alveolar walls, capillaries, bronchi, vessels, and pleura, and served as a useful additional means of defining these structures, particularly in diseased tissues where distortion or destruction had occurred. The basement membrane of new vessels within scar tissue and surrounding smooth muscle bundles in vascular and bronchial walls were readily defined.

Organising pneumonia A biopsy specimen from a localised area of right basal pulmonary consolidation of three months' duration in a patient with dermatomyositis showed large amounts of immunofluorescent type I and type III collagen (of approximately equal intensity) in areas of intra-alveolar and alveolar wall fibrosis.

Sarcoid nodules A similar increase in both collagen types was observed in established sarcoid nodules in lung from a patient with asymptomatic sarcoidosis and 4-8 $\mathrm{mm}$ diameter diffuse nodularity on chest radiograph. This ratio was also present in areas of mild alveolar wall thickening and cellularity, whereas intervening alveolar walls were normal in all respects. Giant-cell-containing islands of mononuclear cells were free of collagen.

Silicosis In pulmonary silicotic nodules, the overall collagen fluorescence was less than that in sarcoid granulomata, particularly in the central hyalinised zones and in the whorled bundles of densely packed collagen (fig 3 ). In these zones, type I was exclusively present, whereas in the outer zones, containing dust-laden macrophages and numerous fibroblasts, both types I and III were present in almost equal proportions. This feature was also observed throughout smaller cellular nodules that lacked the acellular central zone. New vessels were identified in the outer zones by their basement membrane fluorescence. A similar distribution of types I and III collagen was found in the fibrosis compressing and invading vessles.

Pleural plaques Plaques from a patient with asbestosis and pleural mesothelioma contained some fibroblasts and gave strong uniform fluorescence with type I antibodies, but negligible fluorescence with type III.

Fibrous pleural thickening The fibrous pleura from $N$ three patients with systemic lupus erythematosis (SLE) and two patients with cryptogenic fibrosing alveolitis (CFA) with pleuritis were examined. In all cases the major collagen in thickened pleura was type I, but in two patients with SLE and one with CFA, moderate amounts of type III collagen were also present. The patients in whom type JII was found had a short disease history (four, eight and 12 months) and progressive clinical deterioration. The two with SLE showed a striking improvement in symptoms, lung function tests and chest radiography when treated with corticosteroids, 앙 

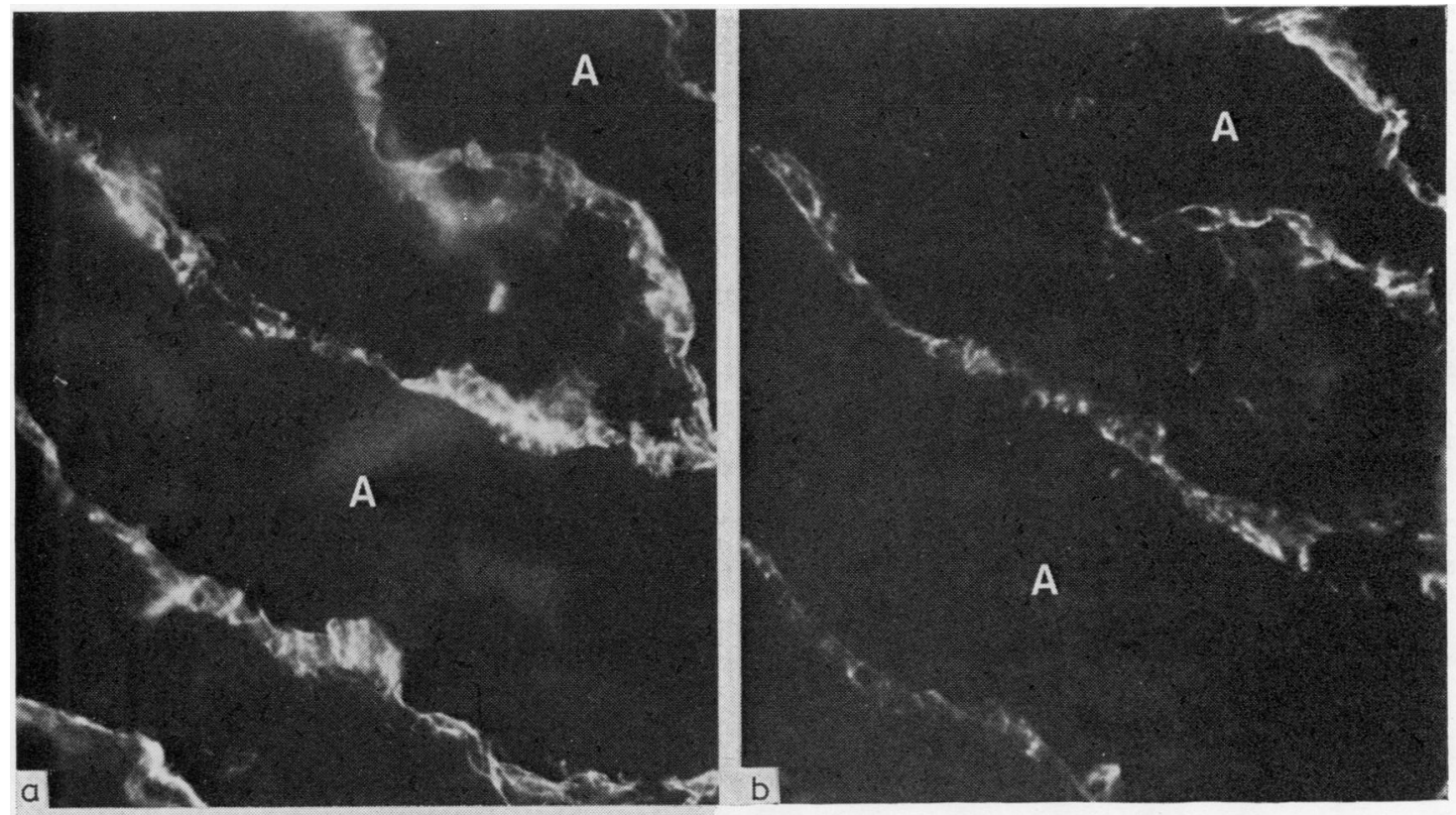

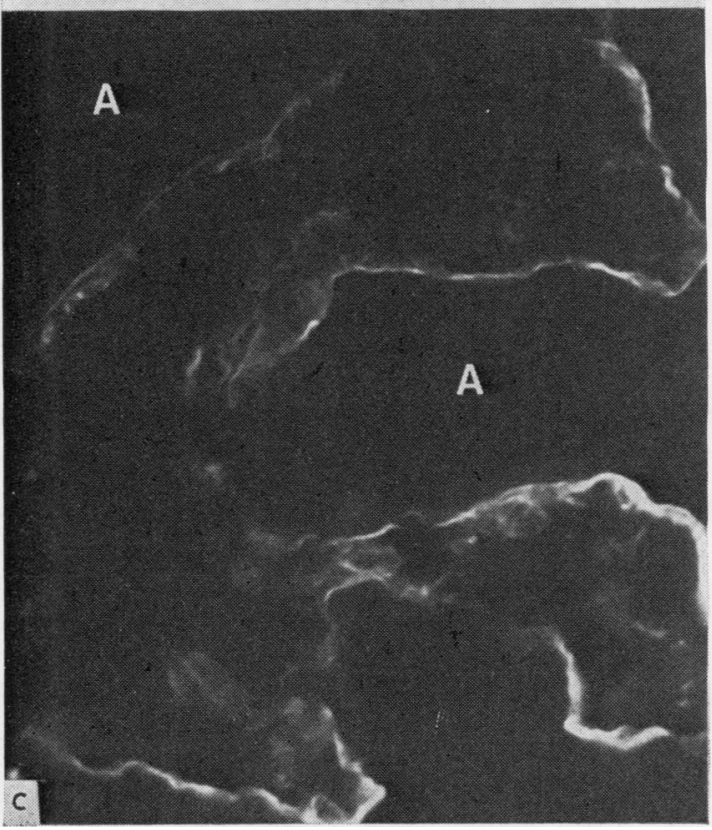

whereas the third did not respond. Patients without demonstrable type III collagen had a longer history (12 months and four years) and a stable clinical course without treatment.

COMPARISON OF HISTOLOGICAL STAINS AND COLLAGEN IMMUNOFLUORESCENCE

In foetal lung, the fluorescence method using either
Fig 2 Photomicrographs of type-specific collagen fluorescence in walls of alveolar ducts from human foetal lung (20 weeks gestation). Purified type-specific antibodies were used in an indirect immunofluorescence method. Air spaces marked A. Photomicrographs $a$ and $b$ show serial sections stained for types I and III collagen respectively. (c) Basement membrane type IV collagen fluorescence in an adjacent area (original magnification $\times 1000$ ).

type I or type III antibodies appeared to be more sensitive for detecting collagen in tissue sections than conventional histological stains. The same was true in adult tissues in areas with increased type III content. In both these circumstances the Masson's trichrome and Miller elastin van Giesen failed to detect some of the smaller deposits of collagen, whereas the pattern of collagen obtained with the 
Table Scores of type I and type III collagen content in human lung

\begin{tabular}{|c|c|c|}
\hline Tissue & Type I collagen & Type III collagen \\
\hline $\begin{array}{l}\text { Foetal: Bronchial cartilage } \\
\text { Alveolar wall } \\
\text { Bronchi and vessels } \\
\text { Pleura and lung septa } \\
\text { Normal adult alveolar wall } \\
\text { Adult pleura. peribronchial, and perivascular connective } \\
\text { tissue } \\
\text { Bronchial submucosa and subintima } \\
\text { Organising pneumonia } \\
\text { Sarcoid nodule: all layers } \\
\text { Silicotic nodule: outer zone } \\
\text { centre } \\
\text { Asbestotic pleural plaque: all layers } \\
\text { Fibrous pleural thickening: } \\
\text { in CFA } \\
\text { in SLE }\end{array}$ & $\begin{array}{l}+++ \\
++ \\
+++ \\
+++ \\
+ \\
++ \\
++ \\
+++ \\
+++ \\
++-+++ \\
++++ \\
+++ \\
++++\end{array}$ & $\begin{array}{l} \pm(\text { Type II }+++) \\
+ \\
++ \\
++ \\
\pm \\
\pm \\
++ \\
++-+++ \\
++-+++ \\
+-++ \\
\pm \\
\pm \\
\pm \\
++\end{array}$ \\
\hline
\end{tabular}

Tissues were stained by an indirect immunofluorescence technique using type-specific collagen antibodies on serial sections.

Semiquantitative scores were based on combined assessment of distribution and intensity of fluorescence in each location, and scored as \pm (equivocal or absent),,+++ , or +++ .

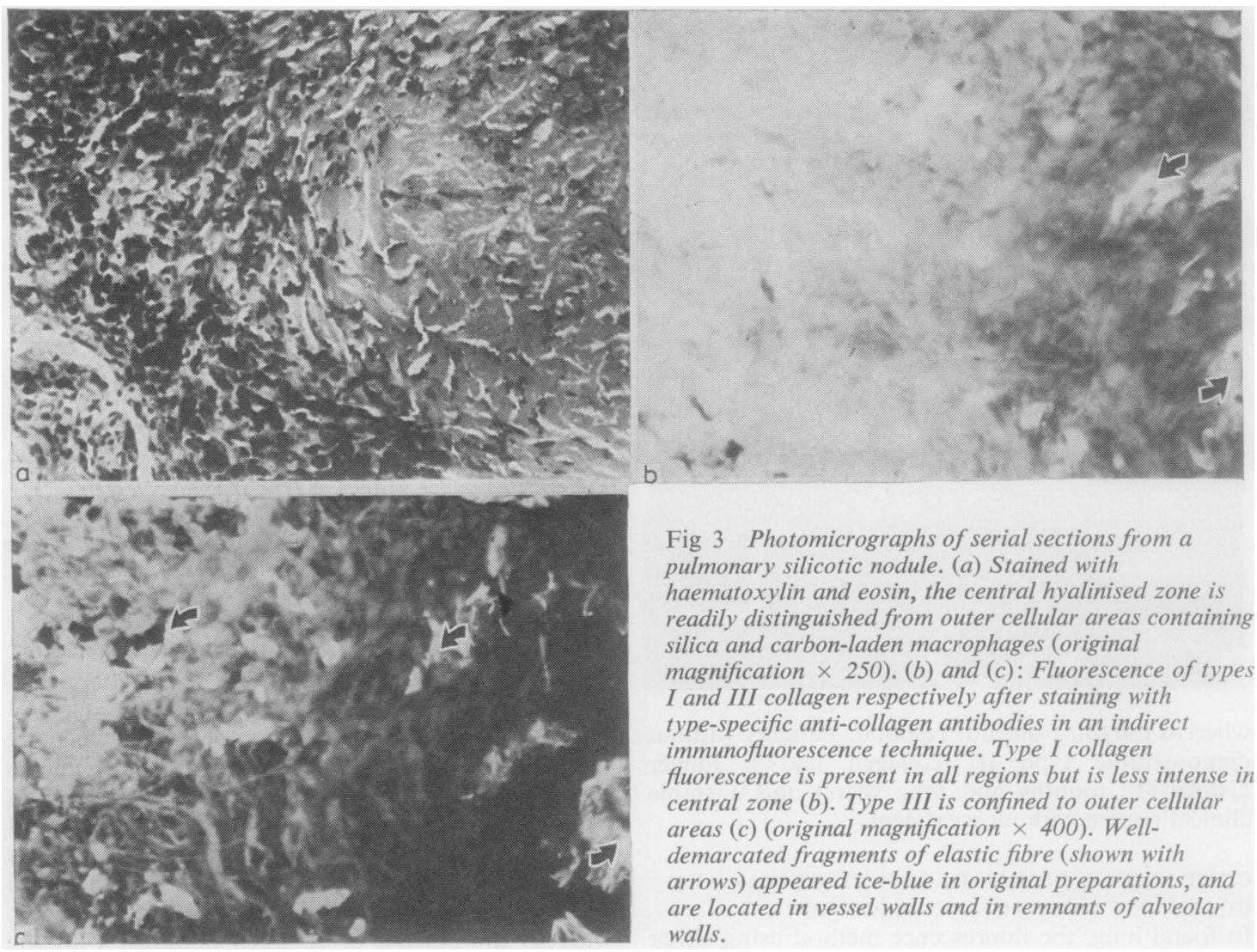
readily distinguished from outer cellular areas containin silica and carbon-laden macrophages (original magnification $\times 250)$. (b) and $(c)$ : Fluorescence of type. $I$ and III collagen respectively after staining with type-specific anti-collagen antibodies in an indirect immunofluorescence technique. Type I collagen central zone (b). Type III is confined to outer cellular areas $(c)$ (original magnification $\times 400)$. Welldemarcated fragments of elastic fibre (shown with arrows) appeared ice-blue in original preparations, and walls. 
silver impregnation method coincided most closely with that of collagen immunofluorescence. Finally, in normal adult lung, and in fibrous tissue with minimal type III collagen, all three stains compared favourably with fluorescence.

\section{Discussion}

Immunofluorescence techniques have been used for the identification of collagen types in specific anatomical sites in several tissues, ${ }^{12} 131819$ but we have found no reports of their application to the study of fibrotic lung disease.

This study confirms that type $I$ is the major collagen type of established fibrous scar tissue in the lung, as it is in other organs. ${ }^{6}$ In addition, on the basis of collagen type fluorescence two distinctive patterns of fibrosis have been identified, the first in sites of established mature fibrous tissue, the second in areas of early active fibrosis. In the former situations, for example in asbestotic pleural plaques, the whorled central zone of silicotic nodules and in peribronchial and perivascular connective tissue, collagen forms large fibre bundles. These are more refractile than loosely arranged collagen and thus display a greater degree of light-blue non-specific autofluorescence in ultraviolet light. Specific fluorescence is obtained with antibodies to type I collagen and individual fibres are coated, giving a "tubular" rather than uniform fluorescent appearance. In addition, the overall intensity of fluorescence is diminished in these sites. The reduced fluorescence and tubular effect is probably the result of fewer accessible antigenic sites on the fibres, because of more cross-linkages, ${ }^{11} 2021$ fibril packing, or changes in connective tissue matrix. Type III collagen is seldom detected in these locations. By contrast, in sites of early or active fibrosis, the content of both type I and type III is increased, and quantitated fluorescence of the latter often approaches that of type I. Other features include a more intense overall fluorescence of both collagen types as a result of uniform coating of collagen fibres with fluorescent antibody complexes, and less non-specific autofluorescence. These sites are usually more cellular and contain variable numbers of fibroblasts and chronic inflammatory cells.

The two patterns frequently coexist in a single lesion, as seen in the silicotic nodule where the central zone is "mature", and the outer cellular zone has features of active fibrogenesis. However in some biopsies, for example from acute organising pneumonia, active sarcoidosis, and fibrous pleurisy of short duration, the fluorescence appearances are sufficiently uniform to permit an overall assessment of early active fibrosis to be made.
The finding in this study that type III collagen increases in sites of early active fibrosis in the lung accords with observations in other organs and tissues. It has been found in immunofluorescence studies of wound healing in children, 18 fresh atherosclerotic intimal fibrosis, ${ }^{22}$ human and experimentally induced liver cirrhosis, 192324 and in biochemical studies of dermal collagen synthesis in response to acute or chronic inflammatory stimuli. ${ }^{25}$ Human embryonic skin fibroblasts have been shown to be capable of simultaneous synthesis of both type I and type III collagen, ${ }^{26}$ and it is probable that in response to inflammation and other stimuli, "invading" or proliferating fibroblasts or possibly myofibroblasts ${ }^{27}$ increase type III collagen synthesis. Bailey et $a^{25}$ found that the proportion of type III collagen in mature rat skin increased from about $10 \%$ to $40 \%$ in acute inflammatory fibrosis.

The physiological implications of changes in collagen ratios are being increasingly recognised. Besides the structural differences between collagen types which can influence mechanical properties of tissues, the various types have different biochemical properties. For example, the cell attachment protein, fibronectin, binds more avidly to type III collagen than to type 1 , II and basement membrane collagens, ${ }^{28}$ and provides the mechanism by which type III collagen induces more platelet aggregation than the other types. ${ }^{2930}$ This may have important consequences in early atherosclerosis, as well as in other lesions. Furthermore, the binding site of fibronectin on collagen corresponds to the specific binding site for mammalian collagenase, suggesting that the binding of fibronectin might play a role in the regulation of different rates of degradation of collagen types. ${ }^{31}$

The comparison of connective tissue stains in this study showed that silver impregnation is the stain of choice for detecting collagen in foetal lung and in early fibrotic lesions. This supports the findings of Huang ${ }^{32}$ in studies of alveolar wall collagen. Controversy exists as to whether argyrophilic connective tissue is all collagenous, ${ }^{32} 33$ but its profusion in immature and embryonic tissues is well recognised, and is not explained by collagen type, fibril size, or glycosaminoglycan content, although it might be related to fibre organisation. ${ }^{8}$ The relatively high type III collagen content in these locations, as shown by immunofluorescence, suggests that a large proportion of argyrophilic fibres are type III collagen. There is, however, as yet no certain information on the relative silver staining properties of types I and III collagen fibres.

There are several potential'sources'of error in the methods used in this study, and precise standardisation is impossible. The chief difficulties are the sub- 
jectivity of histological assessments, particularly those involving immunofluorescence, and the interbatch differences in specificity and affinity of anticollagen and fluorescein-labelled antibodies. Provided that highly purified anticollagen antibodies are used, with certain measures a degree of standardisation can be achieved, which permits at least a valid comparison within a single series. The measures employed in this study included (a) the use of a single batch of anticollagen antibodies and second layer reactants in predetermined dilutions, (b) the use of the same second layer reactant for types I, JI and III collagen antibodies, and (c) the assessment of repeatability and interbatch variation on a standard substrate, and by several examinations of some pathological specimens. In addition, fluorescence microscopy was performed by a single observer who had no previous knowledge of the histopathology or clinical details of each case.

Human foetal lung in the canalicular phase of development proved a valuable substrate for validation of type-specific antibodies to collagen and standardisation of the technique. These measures are an absolute requirement before pathological tissue samples are studied. ${ }^{12} 34$ Human foetal epiphyseal cartilage growth plates have also been used for this purpose. ${ }^{18}$ The value of foetal lung is based on the presence of types I, II, III, and IV collagen at different easily defined locations in the same section, the immaturity of the collagen fibres, and the relative absence of elastic fibres at this stage.

The different locations in which the collagens occur in foetal lung are: types I and II within developing cartilage plates, type III in the same distribution as type I with the exception of cartilage, and type IV collagen exclusively in sites containing basement membranes. The simultaneous presence of types I and II collagen in maturing cartilage plates is of interest since adult cartilage in other sites contains only type II collagen. ${ }^{35}$ There are, however, no reports of detailed biochemistry of adult or foetal bronchial cartilage freed of its fibrous perichondrium. In a study of limb development in chicks, Linsenmayer et $a^{36}$ showed that a transition in collagen type occurred: from type I in the limb bud mesenchyme, to solely type II in tibial diaphysis by day 8 . Later type I reappeared as osteogenesis began. Cartilage plates are found in proximal bronchi from the tenth week of intrauterine development, and their appearance proceeds distally until the end of the canalicular phase. ${ }^{37}$ The maturation of the cartilage matrix takes several weeks longer. ${ }^{37}$ Cartilage development during the canalicular phase might therefore correspond to the transitional phase in chick limb buds described by Linsenmayer et $\mathbf{l}^{36}$ when both type I and type II collagen are present.

A second advantage of using foetal lung in the canalicular phase as a standard substrate is its minimal elastic tissue content. At this stage a small amount is visualised in arterial walls and major airways, but not in alveolar walls. ${ }^{38}$ Elastic fibres are highly refractile and display characteristic ice-blue autofluorescence in ultraviolet light, the intensity of which may interfere with evaluation of the specific fluorescence of adjacent collagen. Third, the collagen in foetal tissue is less mature, has fewer cross-links, and is less tightly packed than in adults. ${ }^{111}$ It therefore stains with predictable intensity. Finally, the availability of foetal lung also commends it for use as a standard substrate, and a single sample can be included in many batches.

In conclusion, the immunohistochemical study of $\vec{\omega}$ collagen is a useful sensitive method for detecting $\mathbb{D}$ small overall increases in lung collagen, possibly at stages at which they are not detected with other connective tissue stains. It also has an important application for defining areas of active or early fibrosis, whether widespread or focal. This is gauged from the increased proportion of type III collagen, the intense uniform fluorescence of both types I and III fibres, and the relative absence of nonspecific collagen autofluorescence. In contrast, late lesions or mature scar tissues are identified by weaker specific fluorescence and more pronounced autofluorescence of the type I collagen fibre bundles, the absence of type III fluorescence, and the relative acellularity of these connective tissue sites. This method is usefully combined with routine histological assessment which has the advantage of defining the cell types present. In some conditions, this information will assist with decisions about treatment, and $x$ this application has recently been assessed in a group of patients with cryptogenic fibrosing alveolitis (unpublished observations).

This work was supported in part by grants from 옥 ICI South Africa (Pharmaceuticals) Ltd, Lilly $\frac{D}{2}$ Industries Ltd, and Dista Pharmaceuticals, England, to whom we are very grateful.

\section{References}

${ }^{1}$ Bradley KH, McConnell SD, Crystal RG. Lung collagen composition and synthesis: characterization and

synthesis with age. $J$ Biol Chem 1974;249:2674-83.
${ }^{2}$ Bradley K, McConnell-Breul S, Crystal RG. Collagen in $\frac{\mathscr{C}}{\mathscr{C}}$ the human lung. J Clin Invest 1975;55:543-50.

${ }^{3}$ Madri JA, Furthmayr H. Isolation and tissue localization of type $\mathrm{AB}_{2}$ collagen from normal lung parenchyma. Am J Pathol 1979;94:323-32.

${ }^{4}$ McLees BD, Schleiter G, Pinnell SR. Isolation of type III collagen from human adult parenchymal lung tissue. Biochemistry 1977;16:185-90.

${ }^{5}$ Seyer JM, Hutcheson ET, Kang AH. Collagen poly 
morphism in idiopathic chronic pulmonary fibrosis. J Clin Invest 1976;57:1498-507.

- Grant ME, Prockop DJ. The biosynthesis of collagen. $N$ Engl J Med 1972;286:194-9.

${ }_{7}$ Epstein EH. [aI (III) $]_{3}$ Human skin collagen: release by pepsin digestion and preponderance in foetal life. $J$ Biol Chem 1974;249:3225-32.

${ }^{8}$ Hay ED, Hasty DL, Kiehnau KL. Fine structure of collagens and their relation to glucosaminoglycans (GAG). In: Gastpar H, Kühn K, Marx R, eds. Collagenplatelet interaction. Proceedings of the First Munich Symposium on Biology of Connective Tissue. Stuttgart: Schattauer, 1978;29-51.

9 Von der Mark K, von der Mark H, Timpl R, Trelstad RL. Immunofluorescent localization of collagen types I, II, and III in the embryonic chick eye. Dev Biol 1977;59: 75-85.

${ }^{10}$ Mayne R, Vail MS, Miller EJ. Characterization of the collagen chains synthesized by cultured smooth muscle cells derived from Rhesus monkey thoracic aorta. Biochemistry 1978;17:446-52.

11 Tanzer ML. Crosslinking. In: Ramachandran GN, Reddi AH, eds. Biochemistry of collagen. New York: Plenum Press, 1976;137-62.

${ }^{12}$ Nowack H, Gay S, Wick G, Becker U, Timpl R. Preparation and use in immunohistology of antibodies specific for type $I$ and type III collagen and procollagen. $J$ Immunol Methods 1976;12:117-24.

${ }^{13}$ Wick G, Furthmayr H, Timpl R. Purified antibodies to collagen: an immunofluorescence study of their reaction with tissue collagen. Int Arch Allergy Appl Immunol $1975 ; 48: 664-79$.

${ }^{14}$ Adelmann BC, Gentner GJ. Dependence of the antibody response of guinea-pigs to collagen on the type of adjuvant and on the conformation of the antigen. $Z$ Immunitaetsforsch Immunobiol 1977;152:369-80.

15 Adelmann BC, Gentner GJ, Hopper K. A sensitive radioimmunoassay for collagen. J Immunol Methods 1973;3: 319-36.

${ }^{16}$ Chadwin CG. A method for the demonstration of reticulin fibres using a modified Glees' silver solution. J Sci Technol 1969;15:56.

${ }^{17}$ Culling CFA. Handbook of histopathological and histochemical techniques. Third edition. London: Butterworths, $1974: 414-5$.

${ }^{18}$ Gay S. Immunohistological studies on collagen type distribution in tissues. In: Gastpar H, Kühn K, Marx R, eds. Collagen-platelet interaction. Proceedings of the First Munich Symposium on Biology of Connective Tissue. Stuttgart: Schattauer, 1978:171-9.

${ }^{19}$ Wick G. Immunofluorescence with specific antisera to collagen and pro-collagen as a new diagnostic tool. In: Gastpar H, Kühn K, Marx R, eds. Collagen-platelet interaction. Proceedings of the First Munich Symposium on Biology of Connective Tissue. Stuttgart: Schattauer, 1978:181-5.

${ }^{20}$ Chvapil M, Kronenthal RL, van Winkle W. Medical and surgical applications of collagen. Int Rev Connect Tissue Res 1973;6:1-63.

${ }^{21}$ Bailey AJ. Some aspects of collagen maturation and fibrosis. Ann Rheum Dis 1977; 36 Suppl:5-7.

${ }^{22}$ Gay S, Balleisen L, Remberger K, Fietzek PP, Adelmann
BC, Kühn K. Immunohistochemical evidence for the presence of collagen type III in human arterial walls, arterial thrombi, and in leucocytes incubated with collagen in vitro. Klin Wochenschr 1975;53:899-902.

${ }^{23}$ Kent G, Gay S, Inouye T, Bahu R, Minick OT, Popper H. Vitamin A-containing lipocytes and formation of type III collagen in liver injury. Proc Natl Acad Sci USA 1976;73:3719-22.

${ }^{24}$ Wick G, Brunner H, Penner E, Timpl R. The diagnostic application of specific antiprocollagen sera: II. Analysis of liver biopsies. Int Arch Allergy Appl Immunol 1978;56:316-24.

${ }^{25}$ Bailey AJ, Sims TJ, Le Lous M, Bazin S. Collagen polymorphism in experimental granulation tissue. Biochem Biophys Res Commun 1972;66:1160-5.

${ }^{26}$ Gay S, Martin GR, Müller PK, Timpl R, Kühn K. Simultaneous synthesis of types I and III collagen by fibroblasts in culture. Proc Natl Acad Sci USA 1976;73: 4037-40.

${ }^{27}$ Gabbiani G, Le Lous M, Bailey AJ, Bazin S, Delauney A. Collagen and myofibroblasts of granulation tissue: a chemical, ultrastructural, and immunologic study. Virchows Arch [B Cell Pathol] 1976;21:133-45.

28 Engvall E, Ruoslahti E, Miller EJ. Affinity of fibronectin to collagens of different genetic types and to fibrinogen. J Exp Med 1978;147:1584-95.

29 Bensusan HB, Koh TL, Henry KG, Murray BA. Culp LA. Evidence that fibronectin is the collagen receptor on platelet membranes. Proc Natl Acad Sci USA 1978;75: 5864-8.

${ }^{30}$ Balleisen L, Gay S, Marx R, Kühn K. Comparative investigation on the influence of human and bovine collagen types I, II and III on the aggregation of human platelets. Klin Wochenschr 1975;53:903-5.

${ }^{31}$ Minor RR. Collagen metabolism: a comparison of diseases of collagen and diseases affecting collagen. Am J Pathol 1980;98:225-80.

${ }^{32}$ Huang TW. Chemical and histochemical studies on human alveolar collagen fibres. Am J Pathol 1977;86: 81-93.

${ }^{33}$ Pras M, Glynn LE. Isolation of a non-collagenous reticulin component and its primary characterization. Br J Exp Pathol 1973;54:449-56.

${ }^{34}$ Becker U, Nowack H, Gay S, Timpl R. Production and specificity of antibodies against the aminoterminal region in bovine type III collagen. Immunology 1976;31 : 57-65.

${ }^{35}$ Nimni M, Deshmukh K. Differences in collagen metabolism between normal and osteoarthritic human articular cartilage. Science 1973;181:751-2.

${ }^{36}$ Linsenmayer TF, Trelstad RL, Toole BP, Gross J. The collagen of osteogenic cartilage in the embryonic chick. Biochem Biophys Res Commun 1973;52:870-6.

${ }^{37}$ Bucher U, Reid L. Development of the intrasegmental bronchial tree: the pattern of branching and development of cartilage at various stages of intra-uterine life. Thorax 1961;16:207-18.

${ }^{38}$ Loosli CG, Potter EL. Pre- and post-natal development of the respiratory portion of the human lung with special reference to elastic fibres. Am Rev Respir Dis 1959;80: 5-23. 